\title{
An investigation of family SES-based inequalities in depressive symptoms from early adolescence to emerging adulthood
}

\author{
K.A.S. Wickrama ${ }^{a}$, Samuel Noh ${ }^{\mathrm{b}}$, and Glen H. Elder ${ }^{\mathrm{C}}$ \\ aDepartment of Human Development And Family Studies lowa State University, United States \\ ${ }^{b}$ Centre for Addiction and Mental Health, University of Toronto, Canada \\ 'University of North Carolina - Chapell Hill, United States
}

\section{Abstract}

Using the life course cumulative advantage/disadvantage (CAD) perspective, this study examines the influence of early family SES on trajectories of depressive symptoms spanning from early adolescence to early adulthood, as well as variations in SES-based inequality in depressive symptoms trajectories over this period. This study looks at direct influences of family SES and SES-age interactions (exposure-dependent CAD mechanisms), as well as indirect influences through SES-linked youth experiences (path-dependent CAD mechanisms) to explain variations in SES-based inequality. Data was derived from the Add Health study- a national longitudinal survey of 14,000 adolescents. Results showed large and significant effects of early family SES and associated factors on depressive symptoms in early adolescence, but diminishing effects in middle and late adolescence, supporting the hypothesis of equalization in adolescent health across levels of SES. Disparities in depression reemerged as adolescents entered adulthood, supporting the view that SES-based health equalization is only a temporary process. These findings also strengthen the concept of life course CAD processes, stemming from family characteristics, coming into play later in life. Early family SES was directly and indirectly related to a set of transition-related risks and challenges during emerging adulthood, to which young adults from families of higher SES responded more effectively than those of lower SES. This paper discusses theoretical and methodological implications of the findings.

\section{Keywords}

Inequalities; Early life course; Depressive symptoms

\section{Introduction}

\begin{abstract}
Social and epidemiological research has documented a strong association between socioeconomic status (SES) and physical and mental health problems (Adler et al., 1994; Chen, Matthews, \& Boyce, 2002; Link \& Phelan, 1995). Individuals of lower SES possess fewer resources and often experience more stressful life events than people of higher SES, contributing to health disparities (Pearlin, 1989; Turner \& Noh, 1983; Turner, Wheaton, \& Lloyd, 1995). More importantly, a growing amount of life course and developmental research has confirmed that childhood family SES exerts lifelong influences, increasing health disparities in later stages of the life course (Robinson, 2001; Ross \& Wu, 1996; Walesman, Gee, \& Geronimus, 2009; Wickrama, Conger, \& Abraham, 2005).
\end{abstract}

(C) 2010 Elsevier Ltd. All rights reserved.

Correspondence to: K.A.S. Wickrama. 
Life course research has increasingly focused on how disadvantages experienced during childhood may regulate health inequalities over the life course (Hatch, 2005; Hayward \& Gorman, 2004; O'Rand, 1996; O'Rand \& Hamil-Luker, 2005; Wilson, Shuey, \& Elder, 2007). Early childhood socioeconomic conditions may initiate a lifelong cumulative advantage/disadvantage (CAD) process (Dannefer, 2003; Merton, 1988) with individuals of lower family SES experiencing more rapid decline or less rapid improvement in health over the life course compared to individuals of higher family SES, leading to widening inequalities and diverging trajectories with age (Hatch, 2005; House, Lantz, \& Herd, 2005; Jackson, 2006; Lynch, 2003; O'Rand \& Hamil-Luker, 2005; Prus, 2007; Ross \& Wu, 1996; Wilson et al., 2007). Such SES-based health inequalities are evident in both physical and mental health domains (Turner et al., 1995; Wickrama, Noh, \& Bryant, 2005).

Most life-course research on mental health disparities has often focused on the SESdepression association in adulthood (Walesman et al., 2009; Wheaton \& Clarke, 2003). Although a large volume of research has focused on adolescent mental health (Conger, Ge, Elder, Lorenz, \& Simons, 1994; Elder, George, \& Shanhan, 1996; Gore \& Aseltine, 2003), only a few studies has specifically investigated the SES-depression association during the period of adolescence (e.g., Meich \& Shanahan, 2000). Adolescence, a sensitive developmental period of rapid changes, adjustments, and life transitions, consists of developmental phases (early, middle, and late adolescence) that are distinguished by physiological markers and core socialization tasks. Developmental studies suggest that emotional trajectories, their association with family SES factors, and consequently, SESbased inequalities vary during different phases of adolescence, as well as during the transition to adulthood (Arnett, 2000; Ge, Lorenz, Conger, Elder, \& Simons, 1994; Kerckhoff, 2002; Larson, Moneta, Richards, \& Wilson, 2002). However, more research is needed to help gain insight about the variation in SES-based inequalities in depressive symptoms over the early life course.

\subsection{Variation in SES-based inequalities: potential life-course mechanisms}

The life course perspective suggests that SES-based health inequality increases with developmental stages through a cumulative advantage/disadvantage (CAD) process producing divergent health trajectories. Life course research has documented several mechanisms involved in CAD process (Wilson et al., 2007). Drawing from life course literature, we have identified several potential mechanisms applicable to the present study.

First, CAD processes may operate through various direct and indirect mechanisms (Wilson et al., 2007). Direct exposure to early family SES and SES-linked family resources (e.g., parenting) creates early SES health-gaps across SES groups (exposure-dependent mechanism). If the influences (the rate of return) of these SES factors remains unchanged over time, the early health-gaps may also maintain over the life course, thus producing parallel SES-group health trajectories (without a divergence or convergence). If the influences of early family SES factors on depressive symptoms increase with age, early health-gaps may widen, producing divergent SES-group health trajectories. This is the exposure by age mechanism of CAD process: higher SES groups gain increasingly larger health advantage or/and lower SES groups experience increasingly larger disadvantage. Conversely, if the direct influence of early family SES factors on depressive symptoms diminishes with age, it may produce convergent trajectories (a reversed CAD process: an equalization).

Second, CAD processes may operate through indirect influences of early family SES and associated resources whereby earlier advantages/disadvantages set in motion a series of cascading age-graded life experiences (path-dependent mechanism) (O'Rand \& HamilLuker, 2005). That is, earlier developmental successes or failures are linked to the quality of 
life experiences in a successively contingent manner, creating a social chain of risks and resources from early adolescence to adulthood (Hayward \& Gorman, 2004; O'Rand \& Hamil-Luker, 2005). Previous research has well documented linkages between age-grade experiences and resources, and family SES characteristics (e.g., Conger et al., 1994; Whitbeck et al., 1997). As in the case of family SES, the influences (rate of return) of SESlinked age-grade life experiences (e.g., school attachment) and SES-linked core life resources (e.g., self-esteem) may change. For example, if the influence of early school attachment on depressive symptoms increases with age, early SES gaps may widen, thus producing divergent depressive symptom trajectories. This is the path by age mechanism of CAD process. Conversely, if the influence of school attachment on depressive symptoms decreases with age (a reversed CAD process), it may produce convergent trajectories (an equalization). We expect deviations from typical CAD processes when family SES factors influence depressive symptom trajectories during adolescence.

\subsection{Study objectives}

Using longitudinal data, this study examines depressive symptom trajectories to understand the ways in which family SES contributes to health inequalities over a period spanning from early adolescence to emerging adulthood. Our study has two specific objectives.

First, we will investigate changing influences of family SES on depressive symptoms over adolescence and emerging adulthood. In order to investigate the overall influence of family SES, we will examine the influences family SES factors corresponding to both 'exposuredependent' and 'path-dependent' mechanisms (Wilson et al., 2007) including family SES characteristics, SES-linked family resources (e.g., effective parenting), SES-linked core life resources (e.g., self-esteem and mastery), and SES-linked age-graded experiences (e.g., school attachment and disruptive events). This objective requires an analyses of individual depressive symptoms trajectories across three developmental segments: early/middle adolescence (12/13-15/16 years), middle/late adolescence (15/16-19/20 years), and emerging adulthood (19/20-25 years).

Second, we will examine the varying magnitude of inequalities across SES-group depressive symptom trajectories over adolescence and emerging adulthood, and the age-related pattern of depressive symptom trajectories (inequalities across SES-group trajectories may vary, while preserving their average curvilinear pattern). To accomplish this objective, we will examine mean trajectories of SES-based groups. In order to assess the magnitude of SESbased inequality, we will also estimate between-SES-group inequality in depressive symptom levels at several age-points. We will discuss analytical strategies used to fulfill objectives in the methods section.

\subsection{Early SES inequalities in depressive symptom trajectories}

Consistent with the exposure-dependent mechanism (Wilson et al., 2007), early family SES characteristics such as parental education, poverty, and race/ethnicity and SES-linked resources largely determine depressive symptom levels in childhood and early adolescence, thus, creating initial SES-depression inequalities (Brody et al., 2006; Conger et al., 1994; Ge et al., 1994; Grunden \& Ernst, 2007; Matjasko, Grunden, \& Ernst, 2007; Miech, Eaton, \& Brennan, 2005; Whitbeck et al., 1997). Particularly, parents with higher education have greater access to social-psychological resources, parenting skills, and information, all of which protect children from the adverse influence of stressful family circumstances and mental health consequences (Whitbeck et al., 1997; Wickrama, Conger, Wallace, \& Elder, 2003; Wickrama \& Noh, 2009). 
Consistent with the family investment model (Meich \& Shanahan, 2000), family socioeconomic disadvantage (lower SES) limits resources and opportunities for youth, including reduced access to quality housing, proper sanitation, vehicles, household equipment, food, and health insurance, resulting in poor physical and mental health. In addition, children in families facing economic hardship often live in disadvantaged communities with poor health, educational, recreational, and social services (Wheaton \& Clarke, 2003; Wickrama \& Bryant, 2003; Williams, 2005).

Consistent with the family stress process model (Conger et al., 1994), stressful daily life experiences associated family socioeconomic disadvantage (lower SES) have psychological consequences for parents (Conger et al., 1994; Whitbeck et al., 1997; Wickrama \& Noh, 2009); distressed parents are more likely to be irritable, authoritarian, and rejecting, often resulting in poor parenting practices (Conger et al., 1994). Negative parental affect (e.g., hostility and rejection) and poor child management (e.g., lack of involvement or supervision and ineffective discipline) are two aspects of poor parenting that often influence adolescent psychopathology (Sroufe, Duggal, Weinfield, \& Carlson, 2000).

Previous research has also documented that family SES characteristics and resources including family economic problems, parental education, and parental practices indirectly influence the level of depressive symptoms of adolescents through children/early adolescents' age-graded experiences such as school attachment and GPA and core life resources, such as early psychological competence (e.g., self-esteem, mastery) (Conger et al., 1994; Conger, Williams, Little, Maysyn, \& Shebloski, 2009; Koivusilta, Rimpelä, \& Kautiainen, 2006; Whitbeck, Simons, Conger, Lorenz, \& Elder, 1991). We hypothesize that family SES factors, including family characteristics, family resources, adolescents' early age-graded experiences, and core life resources, will influence the initial level of depressive symptom trajectories during early adolescence (Hypothesis 1; H1). We expect these influences to produce initial SES inequalities in the levels of depressive symptoms of adolescents.

\subsection{Diminishing SES inequality in depression during early to middle adolescence}

There are reasons to expect that the salience of family SES, SES-linked early experiences, and core life resources for adolescent depressive symptoms begin to diminish with age during adolescence resulting in a decrease in SES-based health inequalities (SES equalization - a reversed CAD process). As several studies have suggested, several countervailing factors including individual autonomy and peer affiliation during adolescence may decrease the salience of family SES factors (Blane et al., 1994; Clausen, 1993; Shanahan, 2000). Particularly, adolescent experiences in school often enable social mixing across socioeconomic lines (Koivusilta et al., 2006). Thus, schools offer adolescents the opportunity to gain life experiences and associated benefits regardless of family SES, which can retard CAD process (West, 1997). In addition, youth experience physical changes during puberty and stress-inducing transformations, diminishing the salience of family SES factors that may contribute to a decrease in SES-based health inequalities (Brooks-Gunn, Graber, \& Paikoff, 1994; Ge et al., 1994). Therefore, during this period it is plausible that adolescents from families of higher SES may not have the expected relative health advantages over adolescents from families of lower SES.

However, other studies suggest that the influence of extra-familial experiences may be limited, especially during early and middle adolescence because high levels of social and racial segregation and homogeneous peer groupings can constrain opportunities for social mixing in school and community settings (Hallinan \& Teixeira, 1987). A lack of extracurricular activities in schools may also reinforce racial and social segregation among students (Moody, 2001). Moreover, adolescents' level of autonomy, peer affiliation, and 
social mixing may also be constrained by structural socioeconomic characteristics of the family. While such constraints are possible, some degree of social mixing across SES classes is expected to occur during early and middle adolescence.

We hypothesize that the influences of family SES factors on depressive symptoms will decrease during early to middle adolescence (Hypothesis 2A; H2A). As a result, we expect a decrease in SES inequality (an equalization) in depressive symptoms during this period.

\subsection{Further diminishing SES inequality in depression trajectories in middle to late adolescence}

The developmental and life course studies also indicate that the effects of early family disadvantage can continue throughout middle and late adolescents by limiting opportunities for educational and occupational success, as well as promoting psychosocial failures such as premature termination of education (Bernhardt, Gahler, \& Goldscheider, 2005; Sampson \& Laub, 1993; Wickrama et al., 2003).

Youth who are unsuccessful in school and have poor motivation and social skills are more likely to experience disruptive life events, such as dropping out of school, unplanned pregnancy, and early cohabitation or marriage. Previous research has shown that adverse family circumstances may push adolescents prematurely into stressful adult roles (Sampson \& Laub, 1993; Wickrama \& Noh, 2009). These disruptive events and circumstances may be associated with adolescents' depressive symptoms, and hence, partly replace the direct impact of family SES on depressive symptoms during middle and late adolescence (Scaramella, Conger, Simons, \& Whitbeck, 1998; Wickrama, Conger, et al. 2005; Wickrama, Noh, et al., 2005).

However, during the late adolescence, their own level of psychosocial maturity as well as school and other institutional support may operate as countervailing factors and may decrease the causal influences of SES-linked age-graded experiences such as disruptive events on depressive symptom levels. As adolescents become older and more independent, some youth may avoid adverse consequences of disruptive life events by making effective choices (Clausen, 1993; Elder et al., 1996; Shanahan, 2000). This may contribute to a reversed CAD process during middle-late adolescence. Thus, we hypothesize that the influences of family SES factors on depressive symptoms decreases with age during middle to late adolescence (Hypothesis $2 B ; H 2 B$ ). As a result, we expect a decrease in SES inequality (an equalization) form depressive symptoms during this period.

\subsection{Reemergence of inequality in depressive symptoms in transition to adulthood}

Meich and Shanahan (2000) found a strong association between family SES characteristics and depressive symptoms in early adulthood, reflecting increased SES-based health inequalities. Beyond adolescence, the CAD process regains momentum. Consistent with the path-dependent mechanism, experiences of successes and failures persist into adulthood and precipitate as key transition failures such as failures to pursue higher education or to gain a full-time employment (Elder, 1998; Hatch, 2005; O'Rand \& Hamil-Luker, 2005). Although some youth escape the consequences of early family adversities and failures by making well-planned and effective choices (Clausen, 1993; Elder et al., 1996; Shanahan, 2000), most youth are unable to escape those consequences and likely to experience key transition failures during the transition to adulthood.

After graduating from, or dropping out of high school, young adults usually either pursue higher education or attempt to gain full-time employment (Gore \& Aseltine, 2003). Individuals without higher education often face low-paying and unstable work (Kerckhoff, 2002). Key transitional experiences, such as higher education and full-time employment, 
may exert strong influences on young adults' depressed mood. More importantly, the detrimental influence of failures in these key life transitional experiences may increase over time contributing to a differentiation trend or reemergence of SES health inequality.

In addition, educational and occupational attainments are directly influenced by parental SES and SES-related social capital during transition to adulthood independent of life experiences during adolescence (Gore \& Aseltine, 2003). Continued familial assistance during early adulthood has increased substantially during the last decade due to longer school attendance and delayed first marriage (Sandefur, Eggerling-Boeck, \& Park, 2005; Schoeni \& Ross, 2005). Family wealth also enhances access to the information and technology required to develop competitive technological skills that can increase employment prospects (Mortimer \& Larson, 2002). Conversely, lower aspirations and limited encouragement from lower SES parents can interfere with both educational and occupational aspirations and attainments (Steinberg, Lamborn, Darling, Mounts, \& Dornbusch, 1994). These family influences during the transition to adulthood may contribute to a reemergence of SES-based health inequality in depressive symptoms. As Osgood, Ruth, Eccles, Jacobs, and Barber (2005, p. 345) stated, "The path one takes typically reflects the social-class values and resources of one's natal family."

Although we expect to find an SES equalization during adolescence, SES inequalities may reemerge in transition to adulthood. Moreover, consistent with path by age mechanisms of the CAD process, SES inequalities may increase with age. That is, we contend that equalization during adolescence is temporary and is attributable to the decreased impact of family SES factors during adolescence (Larson et al., 2002). We hypothesize that the influences of family SES characteristics and SES-linked key transitions on depressive symptoms will increase during the transition to adulthood (Hypothesis 3; H3). As a result, we expect a reemergence of SES inequality during this period.

1.6.1. The pattern or shape of depressive symptom trajectory-Inequalities across youth depressive symptoms trajectories may vary, while preserving the trajectory pattern (shape) over adolescence and emerging adulthood. Previous research has shown that a general curvilinear (convex) pattern in depressive symptoms is apparent in individual, group average, and overall average trajectories, and is largely related to changes in stressful circumstances associated with physical changes and puberty during adolescence (BrooksGunn et al., 1994; Ge et al., 1994). We expect to replicate a typical curvilinear trajectory in depressive symptoms suggested in previous developmental research (Ge et al., 1994; Larson et al., 2002; Moneta, Schneider, \& Csikszentmihalyi, 2001).

\subsection{Race/ethnicity minority status}

It is important to ensure, empirically, that the effects of family SES and associated resources on youth depressive symptoms are estimated net of individual racial/ethnic minority status. Previous research shows that racial/ethnic minority status exhibits influences on health, beginning in childhood and continuing across the life course, regardless of income, education, and family socioeconomic characteristics (Spencer, 2001; Walesman et al., 2009). We anticipate direct, main effects of race/ethnic minority status on youth depressive symptoms. Hence, the regression coefficients of family SES factors and associated resources and risks on depressive symptom trajectories will be assessed while controlling for the influences of race/ethnic minority status. 


\section{Methods}

\subsection{Sample}

Data for this study came from a nationally representative sample of adolescents participating in the National Longitudinal Study of Adolescent Health (Add Health: see title page for a listing of participating organizations). The primary purpose of this multi-agency funded panel study was to investigate adolescent health and health behavior outcomes. Adolescents and parents participating in the Add Health study provided family socioeconomic information during in-home interviews. The data were derived from a complex clustersampling frame of middle and high school students. Stratified sampling procedures yielded 20,745 respondents from 134 middle and high schools. To ensure diversity, the sample was stratified by region, urbanicity, school type (public vs. private), racial composition, and size.

At the first wave of data collection in 1995; 10,600 male (51\%) and 10,145 female (49\%) adolescents ranging in age from 12 to 19 years were interviewed. Nearly 22\% (4500) of the participating households were below the poverty line. At least one parent worked as a manual laborer in $40 \%$ (8300) of the participating families. Approximately $10 \%$ of participating parents did not respond to the parent questionnaire at Wave I. The second and third waves of data collection obtained information from 14,738 adolescents in 1996 and 15,100 youth in 2001 , respectively.

The present analyses used the in-home interview data from all three waves and family-level predictor variables obtained at Wave I. Our study sample included 14,058 adolescents of varying race/ethnicity who provided data in all three waves of data collection: Caucasians (52\%), African-Americans (20\%), Hispanics (17\%), Asians (8\%), and Native Americans (3\%). Of the respondents, $49.8 \%$ were male and $50.2 \%$ were female. Nearly $11 \%$ of the participating households received food stamps. The median education levels of mothers and fathers were high school or GED completion. At least one parent worked as a manual worker (craftsperson, mechanic, laborer or service, factory or transportation worker) in $29 \%$ of the participating families. These descriptive statistics were not significantly different from those of Wave I respondents. Descriptive statistics of study variables based on this sample are presented in Tables 1 and 3 .

We performed several analyses to examine the influence of attrition data in the sample. Our findings showed that adolescents who participated in all three waves were slightly younger. Based on a comprehensive attrition analysis of Add Health data, Chantala, Kalsbeek, and Andraca (2004) reported that the estimated attrition bias in Wave III is very small for Wave 1 data. They examined demographic characteristics, school experiences, health reports, and attitudes, and found that the attrition bias was less than $0.5 \%$ for most of the items. Our study sample of 14,058 adolescents had missing data for variables ranging from $0.1 \%$ (adult education) to $20 \%$ (paternal education for two parent families). GPA and involved parenting had approximately 5\% and $8 \%$ missing values, respectively. All other predictors had less than $1 \%$ missing values. We imputed data for predictor variables using expectation maximization algorithm in SAS MI procedure (Allison, 2001).

We also examined potential cohort differences since cohort effects might obscure the true pattern of symptom trajectories. Specifically, we examined potential cohort differences for variations in the level and slope of depressive symptom trajectories. In the study sample, older cohorts showed slightly higher depressive symptom levels relative to younger cohorts; however, these differences are not significant. 


\subsection{Measurements}

\subsubsection{Family socioeconomic characteristics}

2.2.1.1. Family poverty: At Wave 1 , parents responded to five dichotomously scored $(0=$ no, $1=$ yes) hardship items assessing whether any member of the household received social service benefits including social security, supplemental security income, aid to families with dependent children, food stamps, or housing subsidies. Summing responses to these five items yielded an internally consistent $(K R-20=0.85)$ index of family poverty measure ranging from 0 to 5 . Standardized scores on this index ranged from -0.48 to 4.52 , with higher scores reflecting greater economic hardship.

2.2.1.2. Parental education: At Wave 1, the responding parent reported the education level of both parents. Ordinal level education categories were generated based on the original response categories for formal education: $0=$ never went to school, $1=$ eighth grade or less, $2=$ more than eighth grade but did not graduate from high school, $3=$ from high school equivalent to less than college degree, $4=$ graduated from a college or university, $5=$ professional training beyond four-year college or university. The higher value of mother and father education level served as an index of parental education in each family. Maternal education was taken as the parental education index in the $1100(8 \%)$ families that were headed by a single female.

\subsubsection{Family resources}

2.2.2.1. Nurturing/involved parenting: Adolescents responded to five items using a 5point scale anchored with "strongly agree" (1) and "strongly disagree" (5). Adolescents were asked whether parents expressed warmth and love, encouraged independence, and explained why something the adolescent had done was wrong. Two additional items asked adolescents whether they were satisfied with: (1) the way their parents communicated with each other, and (2) how satisfied they were overall with their relationship with their parents. Ratings for adolescents' responses to items regarding both mother and father were summed to create a single score in which high scores reflected involved parenting. Separate indices created from items regarding mothers and fathers both possessed adequate internal consistency ( $\alpha=0.90$ and $a=0.85$, respectively), as did the combined involved parenting index ( $\alpha=0.90)$. Responses were doubled for families headed by a single parent.

\subsubsection{Early adolescent experience and core life resources-Adolescents'} education competency was captured by adolescent-reported Grade Point Average and attachment to the school.

2.2.3.1. Grade point average (GPA): At Wave 1, adolescents reported recent grades in mathematics, social studies, and science classes at school. Letter grades reported during Wave 1 interviews were transformed into a 4-point numerical scale (i.e., $\mathrm{A}=4, \mathrm{~B}=3, \mathrm{C}=$ $2, \mathrm{D}=1)$ and summed to construct a measure of school performance.

2.2.3.2. School attachment: At Wave 1, adolescents responded to five items assessing perceptions of the schools they were currently attending. Participants were asked to indicate whether they felt as though they were part of their school, students at school were prejudiced, they were happy to be at their school, teachers treated them fairly, and they felt safe at school. Participants responded to each item using a 5-point scale anchored with "strongly agree" (1) and "strongly disagree" (5). Summing responses after reverse coding items assessing negative feelings yielded a measure of school attachment that possessed adequate internal consistency $(\alpha=0.75)$. 
2.2.3.3. Self-esteem: At Wave 2, participants responded to eight self-esteem items including items from the Rosen-berg (1965) scale. These items assessed adolescents' feelings of self worth (e.g., "You have a lot to be proud of," "You have a lot of good qualities," and "You feel loved and wanted") on a scale ranging from 1 (strongly disagree) to 5 (strongly agree). Summing scores for all items yielded an index of self-esteem that possessed good internal consistency $(\alpha=0.90)$.

2.2.3.4. Mastery: At Wave 2, participants responded to five items assessing adolescents' feelings of mastery and problem-solving skills (e.g., "When you get what you want, it's usually because you worked hard for it," "You usually go out of your way to avoid having to deal with problems in your life," and "Difficult problems make you very upset") on a scale ranging from 1 (strongly disagree) to 5 (strongly agree). Summing scores for all items (after reversed coding negative items) yielded an index of mastery that possessed good internal consistency $(\alpha=0.78)$.

\subsubsection{Mid-adolescent experiences}

2.2.4.1. Disruptive transition: Disruptive transition to adulthood was indexed by counting adolescents' early life experiences $(1=$ yes, $0=$ no) in Waves 1 and 2 . The experiences included age at first sexual intercourse, pregnancy, marriage or cohabitation, dropping out of school, leaving home, and full-time employment (more than $30 \mathrm{~h}$ per week when youth were school age; less than 19 years of age). Ages at first sexual intercourse, pregnancy, marriage or cohabitation, and leaving home, were compared with national normative ages. The average age of first sexual intercourse among males and females in the United States is 16 (Centers for Disease Control and Prevention, 1996) and the average childbearing age near the start of the decade was 24.6 years (Mathews \& Hamilton, 2002). In the United States, the average age that young adults leave home is 21.1 years (Kreiter, 2003). All the events that occurred before the normative ages were considered as disruptive transition events. This disruptive transition index ranged from 0 to 6 , with a mean of 0.35 . A score of 0 indicates that respondents have not experienced any of the disruptive events (zero level of disruptive transition).

2.2.4.2. Peer relations: At Wave 2, peer relations was assessed by counting responses to 20 items which asked whether they hung around with friends after school during the past seven days, and during the past weekend (yes $=1$, no $=0$ ). These questions were asked in relation to a maximum of five male and five female friends that were reported by adolescents. Responses were summed to create an index.

\subsubsection{Emerging adulthood experiences}

2.2.5.1. Young adult education: At Wave 3 (2001/2002), participants indicated the highest grade they had completed in school. By this year, all the respondents were older than the typical age required to complete high school. Because the reported highest grade was truncated against respondents who were still continuing their education after high school, four ordinal categories of young adult education were created, reducing the truncation; $0=$ less than grade 8 completed, 1 = eighth grade completed, $2=$ grade 9,10 , or 11 completed, 3 $=$ high school completed, $4=$ higher than high school. This ordinal level measure served as an indicator of adult education.

2.2.5.2. Student status: Participants who reported that they were attending school full-time at the Wave 3 assessment were considered students. 
2.2.5.3. Low employment status: Participants who reported that they were either employed without completing their high school education or unemployed at the Wave 3 interview were considered as having low employment status.

2.2.5.4. Depressive symptoms: Participants responded to eight items from the Center for Epidemiological Studies of Depression Scale (CES-D; Radloff, 1977). CES-D items assessed the frequency of adolescents' feelings of distress (e.g., "felt depressed and sad") during the past week on a scale ranging from 0 (never or rarely) to 3 (most of the time or all of the time). Summing scores for all items after reversing those that tap positive affect (opposite of depressive symptoms) yielded an index of depressive symptoms that ranged from 0 to 24. Previous research demonstrates that the CES-D is a psychometrically sound instrument for measuring adolescent distress (Noh, Beiser, Kaspar, Hou, \& Rummens, 1999; Radloff, 1991; Wickrama et al., 2003). The Wave 3 survey was limited to 8 items of the CES-D instrument because the composite measure that constitutes these items provided acceptable psychometric properties. The 8-item measure possessed adequate internal consistency across all study waves (all $a>0.76$ ).

\subsection{Analytic strategy}

Respondents who were 13 to 18 years of age in 1995 became 14 to 19 years of age in 1996, and 19 to 23 years in 2001. Rather than merging data by wave, information was restructured based on the chronological age of respondents (i.e., 13, 14, .., 23 years). For example, information of 13 years of age in 1995, 1996, and 2001 was combined regardless of the year of data collection. Similarly, information of $14,15,16, \ldots, 23$ years of age was combined based on the chronological age thereby combining cross-sectional and longitudinal data to produce a data set spanning a longer developmental period from the ages of 13 to 23 years (Duncan, Duncan, Strycker, Li, \& Alpert, 1999).

This restructuring yielded an accelerated sequential cohort design that allowed linkage of adjacent segments of limited longitudinal data from different birth cohorts, assuming the same developmental trend occurs in each cohort. Such a design approximates a long-term longitudinal study by simultaneously conducting and connecting several short-term longitudinal studies of different cohorts. Accelerated sequential cohort designs provide findings similar to those obtained from true longitudinal cohort designs when estimating growth curves (Duncan et al., 1999). Table 1 shows the sample sizes and descriptive statistics for the age-based depressive symptoms in the restructured data. Adolescents who provided sequential data for each age segment were used for multilevel regression analysis. We applied several analytical techniques to test our hypotheses.

\subsection{Investigating objective 1: changing influences of family SES factors on depressive symptoms (H1, H2A, H2B, H3)}

Our preliminary analyses showed that three distinct linear slope segments corresponding to early/middle adolescence (ages 13-16), middle/late adolescence (ages 16-20), and emerging adulthood (ages 20-23), exist in the data (Raudenbush \& Bryk, 2002) (We will discuss this analyses in the results section). Thus, we analyzed different linear slope segments of depressive symptoms for early-mid adolescence, mid-late adolescence, and emerging adulthood separately (as separate linear growth curves). To do so, we first estimated growth curve models for each of the identified symptom trajectory segments.

The model that captures the intra-individual change in depressive symptoms with age (time) for an individual can be written as follows (age is considered as the time):1st Level Model (for an individual): 
This first level intra-individual model predicts the depressive symptoms of an individual $(p)$ at his or her age $(A G E)$. Parameters $\beta_{0}$ and $\beta_{1}$ are the individual-specific initial level and rate of change (slope).

Second, we explain variations in growth curve parameters $\beta_{0}$ (the initial level) and $\beta_{1}$ (slope) using SES factors, according to the following equations. $E$ reflects SES-linked age-graded life experiences, or core life resources, and how SES reflects family SES markers.

2nd Level Model (between individuals):

$$
\begin{gathered}
\beta_{0 p}=\gamma_{00}+\gamma_{01}(S E S)+\gamma_{02}(E)++U_{0 p} \\
\beta_{1 p}=\gamma_{10}+\gamma_{11}(S E S)+\gamma_{12}(E)+U_{1 p}
\end{gathered}
$$

Combined equation:

$Y_{p}=\gamma_{01}(S E S)+\gamma_{02}(E)+\gamma_{10}(A G E)+\gamma_{11}(S E S \times A G E)+\gamma_{12}(E \times A G E)+A G E \times U_{1 p}+U_{0 p}+r$

The second level equations and the combined equation coefficients $\gamma_{10}, \gamma_{01}$, and $\gamma_{02}$, reflect influences of age (time), family SES, and SES-linked experiences or resources on the level of depressive symptoms ('exposure' and 'pathway' mechanisms, respectively). Particularly, $V_{10}$ (age or time effect) reflects rate of change in depressives symptoms or slope of trajectories. These additive influences create the initial SES gap in the levels of depressive symptoms (Hypothesis 1). In order to examine mediation, we will estimate incremental models by incrementally adding predictors. In these incremental models, decreases in the influences of family SES characteristics $\gamma_{11}$ when SES-linked life experiences or resources are added to the model reflect partial mediation of family SES influences. These mediations are evidence for the associations between family SES and life experiences or resources.

Interaction terms with age with $\gamma_{11}$ and $\gamma_{12}$ reflect the effects of SES factors on slope ('exposure by age' and 'pathway by age' mechanisms, respectively), that contribute to the diminishing/increasing effect of SES and life experiences over time. These age-interaction terms (effects on slope) reflect the potential variation in family SES-based inequality over time corresponding to Hypotheses 2A, 2, and 3. For positive life experiences or resources, positive coefficient for the interaction term indicates an increase in inequality (a typical CAD process leads to divergence of trajectories) whereas negative coefficient indicates a decrease in inequality (a reversed CAD process lead to convergence of trajectories). We used SAS Proc Mixed for model estimation to account for both clustering and complex study design due to the school-based sampling of the Add Health study (Chantala et al., 2004).

We also examined the associations between family SES characteristics and adolescent life experiences and core life resources by comparing means of life experiences and core resources across family SES-groups.

\subsubsection{Investigating objective 2 : examining the magnitude of inequalities} across SES-groups and the pattern-We plotted age-specific mean depression values across early adolescence and emerging adulthood (ages 13 to 23) for different SES-based groups and examined the magnitude of inequalities across group trajectories. For example, 
we plotted group mean depressive symptom trajectories for three levels of parental formal education and for three levels of family poverty.

We also assessed (quantified) SES inequalities in depressive symptoms in relation to parental education and family of origin poverty groups by estimating the intra-class correlation between individuals at important ages: the ratio of between-group variance to the total inter-individual variance according to ANOVA at different ages (ICC; Harper \& Lynch, 2006). ICC is a measure of heterogeneity between groups (Raudenbush \& Bryk, 2002). Total inter-individual variance (TOTV) in depressive symptoms at a given age consists of between-group variance and within-group variance (WITHV) such that TOTV = $\mathrm{BGV}+\mathrm{WITHV}$. The ICC is the proportion of the between-group variance to the total variance, ICC $=\mathrm{BGV} / \mathrm{TOTV}$, thus serving as an indicator of between-SES-group inequality (relative to the total inter-individual variance). We estimated ICC at the trajectory turning points observed in mean trajectory plots (i.e., ages 13, 16/17, 19/20, and 23). If our hypothesized trend of equalization in adolescence and differentiation in emerging adulthood is supported by the data, ICC indicators should follow the same trend (decreasing in adolescence and increasing in emerging adulthood).

\section{Analysis and results}

\subsection{Investigating objective 1: changing influences of family SES factors on depressive symptoms (H1, H2A, H2B, H3)}

Our first objective was to examine changing influences of family SES factors with age over adolescence and emerging adulthood. As described in the analysis section, our preliminary analyses focused on identifying distinct potential slope segments exist in the data.

\subsection{Preliminary analyses: exploring slope segments in depressive symptoms trajectories}

We estimated a continuous growth curve of depressive symptoms for 13-23 year age-period with three distinct slope segments corresponding to early/middle adolescence (ages 13-16), middle/late adolescence (ages 16-20), and emerging adulthood (ages 20-23) (Raudenbush $\&$ Bryk, 2002). This incremental slope model with three segments showed a better fit with the data than other alternative forms growth curves with quadratic or overall linear slopes (a decrease in Aiken Information Criterea, AIC, from 166,716 to 166,243). Results from the incremental growth curve model indicated that, consistent with group mean plots, the slope means of the three segments correspond to the convex trajectory shape, with a positive, or increasing, slope in early/middle adolescence (0.11) and a downward, or decreasing, slope in both middle/late adolescence $(-0.48)$ and emerging adulthood $(-0.19)$.

\subsection{Examining each age segment of depressive symptoms trajectories}

Given the evidence supporting the distinction between the three trajectory segments, we performed a separate analysis for each segment. Results of the analyses are shown in Table 2: early-middle adolescence (13-16 years, $N=3141$ ), middle-late adolescence (16-20 years, $N=2564$ ), and emerging adulthood (20 or more years, $N=1901$ ). All of the segmentspecific regression (growth curve) models included age, gender, race/ethnicity, family SES markers, and parenting as predictors. In addition, all models included SES-linked core life resources, such as psychological competencies (self-esteem and mastery), as predictors. All the regression coefficients are interpreted as discussed in the analytical strategy section. Regression coefficients for family SES characteristics $\gamma_{01}$ and SES-linked life experiences and core life resources $V_{02}$ are provided in Table 2. Some age-related experiences varied in applicability across the segments. For example, while early educational competencies (GPA and school attachment) and peer relations were included in the first two segments, and disruptive transition events was only included in the analyses of the two older, age- 
appropriate segments. In addition, young adult education and low employment status applied only to the emerging adulthood segment.

Decreases in the influences of family SES characteristics from M1 to M2 within any particular segment reflect partial mediation of family SES influences by SES-linked life experiences. Direct influences of family SES characteristics and life experiences in both models reflect differences in initial depressive symptom levels (e.g., early adolescence in the first segment). All models show that family SES characteristics and race/ethnicity significantly influence depressive symptom levels across all developmental stages.

Results for the mediation models (M1 and M2) in early-middle adolescence indicates that involved parenting, GPA, school attachment, self-esteem, and mastery relate significantly to depressive symptom levels. These age-graded experiences (i.e., mediating factors) accounted for $38 \%$ of parental education effect (reduced from -0.61 in M1 to -0.38 in M2) and $49 \%$ of family poverty effect (reduced from 0.41 in M1 to 0.21 in M2). These are statistically significant reductions in the effects of family SES characteristics. These results also provide evidence for the associations (linkages) between family SES characteristics, and age-graded experiences and core life resources.

We were particularly interested in explaining changes in family SES-based inequality over time that reflect equalization or differentiation. As discussed in the analyses section, we expected that the interactions between (1) family SES characteristics and age $\left(\gamma_{11}\right)$ and (2) SES-linked factors and age $\left(\gamma_{12}\right)$ correspond to the influences on slope of trajectories and would contribute to changes in family SES-based inequality. To examine this possibility, we computed these interaction terms and entered one term at a time to $\mathrm{M} 2$ in each segment. Panel B of Table 2 presents only the statistically significant results from these analyses, but it is important to note that the interacting influences within any single model come from separate analyses of each interaction effect.

As shown in panel $\mathrm{B}$ of Table 2, significant positive interactions between age and parental education (0.12), parenting (0.03), self-esteem (0.06), mastery (0.05), and school attachment (0.04) suggest that the protective effects of these SES factors diminish during early/middle adolescence, contributing to an equalization of SES-based inequality in depressive symptoms.

The mediation models (M1 and M2) for the middle/late adolescence segment was identical to the mediation model in the younger segment, except for the addition of disrupted transition events and an important extra-familial factor, peer relations. Only the influence of parental education was partly reduced in a manner similar to that of the first segment, but the coefficient remained statistically significant. Although disrupted transition events exerted a strong direct influence on depressive symptoms during this period, influences of the other mediators during middle/late adolescence were weaker than the influences in early/middle adolescence. Peer relations did not show any significant influence on adolescent depressive symptoms. Also, the interactions between disrupted transition and self-esteem, and disrupted transition and mastery were not significant.

As shown in Panel B of Table 2, the significant interactions involving age suggest that the protective effects of parental education, involved parenting, school attachment, mastery, and self-esteem diminish over time during middle/late adolescence. Because these life experiences are closely associated with family SES, the diminishing influences suggest further contribution to the equalization of depressive symptoms during middle/late adolescence. 
Results for the emerging adulthood segment appear in the last two columns of Table 2.

Model M1 shows that race/ethnicity and family SES factors significantly influence depressive symptoms. The absence of significant interactions between age and family SES factors in Model M2 indicates that the influences of these factors no longer diminish in emerging adulthood. Instead, results from Model M2 indicate that young adult education level and low employment status exert strong influences on depressive symptom levels. Inclusion of these factors in the model partly mediates the effects of parental education and family of origin poverty ( $67 \%$ and $36 \%$, respectively). The significant positive interaction between low employment status and time indicates that the detrimental influence of low employment status increases over time (the influence on the slope), which may contribute to the reemergence of SES inequality in depressive symptom trajectories during young adulthood.

In order to examine the association between adolescents' SES-linked age-graded experiences and the family SES levels, we examined mean levels of all aged-graded experiences by family SES-based groups. Results shown in Table 3 suggest modest associations between family SES, core life resources (self-esteem and mastery), and agegraded experiences (GPA, school attachment, disrupted transition, educational achievement, and low-occupation).

\subsection{SES-based group trajectories of depressive symptoms}

The second objective of the study was to examine the influence of family SES on depressive symptom trajectories across early adolescence and emerging adulthood (ages 13 to 23). Overall age-specific means (average levels) computed using restructured data (14,058 adolescents) based on chronological age are shown in Table 1. As expected, these overall means show a curvilinear pattern of average depressive symptom levels over adolescence. In order to examine the SES-based inequalities, we plotted mean depressive symptom trajectories for different SES groups. Fig. 1 shows group mean depressive symptom trajectories for three levels of parental formal education defined as low $(<$ less than high school completion), medium (high school completion up to partial college or university), and high (university degree or more).

Three main observations can be made from Fig. 1 in regard to the relationship between early family SES as measured by parental education and depressive symptom trajectories. First, the convex curvilinear shape of each group trajectory, including the overall mean trajectory, replicates at all levels of parental education. Overall means of depressive symptoms show an increase during early/middle adolescence, decline during middle/late adolescence, and plateau at low levels in emerging adulthood. This trend suggests the presence of distinct agespecific segments of the depressive symptoms trajectories. Thus, the general curvilinear pattern of the group mean trajectories (developmental trend) appears to be independent of parental education across adolescence. Second, in regard to parental education, youth from lower SES groups show consistently higher depressive symptom levels than youth from higher SES groups at all ages (vertical differences across group trajectories). Third, Fig. 1 indicates that SES-based disparity in depression in relation to parental education gradually decreases, reaching the lowest degree at ages 19-20, but reemerges in early adulthood.

We also plotted mean trajectories for three levels of poverty in the family of origin, high poverty (family poverty index scores of 3 or greater), poverty (family poverty index scores of 1 or 2), and low or not in poverty (family poverty index scores of zero). As in the case of parental education, these plots also clearly showed (a) a similar curvilinear pattern of trajectories and (b) that youth from lowest SES-group experience consistently highest depressive symptom levels than youth from other SES groups at all ages. However, as in the case of parental education, the differences in group trajectories did not show significant 
equalization and differentiation trends in SES-based disparity in depression over adolescence and emerging adulthood. Thus, we report the magnitude of SES-group inequality in depression symptoms over adolescence and emerging adulthood only in relation to parental education.

\subsubsection{Examine the varying magnitude of inequalities across SES-group depressive symptom trajectories-Our second objective was to assess trends in} family SES inequality over adolescence and emerging adulthood. We assessed SES inequalities in depressive symptoms in relation to parental education by examining both the between-group variances (BGV) and the intra-class correlation (ICC; Harper \& Lynch, 2006). Estimates of the BGV and the ICC at the average trajectory turning points (i.e., ages 13, 16/17, 19/20, and 23) appear below the mean trajectory plots in Fig. 1. The betweengroup variability (BGV) for parental education showed a gradual and steady decrease from ages 13 to 20 (0.97 to 0.25 ), reflecting a decline in the differences in depressive symptoms due to parental education during this time; it also showed an increase from ages 20 to 23 ( 0.25 to 0.46$)$, indicating an increase in the differences in depressive symptoms due to parental education (Fig. 1).

More importantly, the relative contribution of BGV to the total variance, TOTV (i.e., the ICC), indicated a significant decrease from ages 13 to 20 (0.074 to 0.017$)$, reflecting a decline in the relative contribution of BGV to total variability (TOTV) in depressive symptoms due to parental education (SES equalization). However, a significant increase from ages 19/20 to 23 ( 0.017 to 0.032 ), reflected an increase in the relative contribution of $\mathrm{BGV}$ to total variability in depressive symptoms due to parental education in emerging adulthood (SES differentiation). Standard errors of ICC were calculated based on the formula given by Donner (1986) using average group sizes. This formula has been derived using Z-transformation because ICC is not a normally distributed quantity (Donner, 1986). The ICC at age 20/19 was significantly lower than ICC at age 13 (denoted by a), than ICC at 16/17 (denoted by b), and than ICC at age 23 (denoted by c) (Fig. 1).

\section{Discussion}

Life course theorists contend that childhood advantages related to the family of origin initiate a cumulative advantage/disadvantage (CAD) process that produces increasing SESbased health inequality over the life course. However, there has been a noticeable gap in the existing empirical literature regarding variation in SES-based mental health inequality, particularly across the early life course. Thus, this study focused on SES-based inequality in depressive symptom trajectories during the periods of adolescence and early adulthood. Our study had two specific objectives. The first objective was to examine change in the influences of family SES factors on youth depressive symptoms over this period. The second objective was to examine the patterning of depressive symptom trajectories, and to examine and assess magnitude of SES-based inequalities over adolescence and emerging adulthood. In this study, we examined the influences of parental education and family poverty as markers of family SES.

\subsection{Examining changes in the influences of SES factors with age}

The findings show that the family SES factors including parental education, family poverty, and family SES-linked age-graded experiences and core life resources influence the level (additive effects) and rate of change (interaction effects with age) in depressive symptoms trajectories in all three age segments. The results also showed that different family resources and age-graded experiences partially mediate the influence of family SES in different age segments. As expected, involved parenting, as well as educational (GPA and school attachment) and psychological (self-esteem and mastery) competencies, mediate the 
influence of family SES on depressive symptoms beginning in early adolescence. During middle adolescence, early disruptive transition events also partially mediate the influence of family SES on levels of depressive symptoms. That is, family SES exerts a persistent influence on youth depressive symptoms directly and indirectly through SES-linked experiences and core life resources. However, the interaction between age and parental education demonstrates the diminishing influence of parental education, reflecting SES equalization during this period. Interaction terms between age and parenting, GPA, school attachment, self-esteem, mastery, and disrupted transition events also demonstrate the diminishing influence of age-graded experiences on depressive symptoms from early to late adolescence. Since family resources, age-graded experiences, and core life resources have been shown to be influenced by family SES (as evident by group differences shown in Table 3 and mediational influences in Table 2), the diminishing influences of these experiences on depressive symptoms partly reflect the diminishing influence of family SES on depressive symptoms contributing to an equalization trend during adolescence.

However, beyond adolescence, the absence of such interaction effects with age indicates a cessation of the diminishing influences of family SES on depressive symptoms. Instead, family SES-based health inequalities reemerged upon entry into adulthood suggesting that life course processes stemming from early adversities gain momentum in young adulthood. This finding supports the view that equalization is only a short-term process (during adolescence) within a long-term divergent trend. The reemergence of SES differentiation in depression may occur through both exposure-dependent and pathway-dependent mechanisms. The influences of family SES does not diminish in the transition to adulthood, showing a regained exposure to family SES. Furthermore, the early experiences of failures influenced by family SES may precipitate as stressful transitional difficulties in the transition to adulthood. Family SES also directly influences stressful life experiences, such as low employment. Moreover, these stressful experiences have shown increasing influence over young adulthood contributing to reemergence of SES inequalities. Since young adults' educational and occupational attainment is relatively stable, this differentiation process may continue throughout the latter stages of adulthood.

Previous research has shown that some youth may avoid adverse consequences of disruptive life events by making effective choices, escaping the social chain of risks and resources (Clausen, 1993; Elder et al., 1996; Shanahan, 2000). However, the results did not show any significant moderating effects of self-esteem and mastery on the association between disrupted transition and adolescent depressive symptoms. This may be attributed to the fact that our measures of self-esteem and mastery may not capture adolescents' resilience against adverse life experiences.

The results showed that racial/ethnic minority group membership (African-American, Hispanic, and Asian) exerts an adverse influence on youths' mental health throughout adolescence and emerging adulthood. These are unique influences even after taking into account family SES and SES-linked resources/risks. However, the absence of an interaction between minority status and age suggest that during the early life course the influence of minority status is relatively unchanged over the early life course. Future research should further investigate the socio-psychological mechanisms through which race/ethnicity status influences youths' depressive symptom trajectories and the variation in race/ethnic differences in youth depressive symptoms over the early life course.

\subsection{Pattern and the magnitude of SES inequality in depressive symptom trajectories}

As shown by previous developmental research, overall averages and all SES groups, showed a curvilinear trajectory (Ge et al., 1994; Larson et al., 2002). More importantly, SES-based group trajectories (Fig. 1) showed an equalization trend during adolescence, cessation of the 
equalization by late adolescence, and a differentiation trend beginning in early adulthood. Our findings partially support assertions that the equalization process is temporary and confined to adolescence (Kerckhoff, 2002; Power, Hertzman, Matthews, \& Manor, 1997; West, 1997). Life course processes stemming from early family conditions come into play later in the life course.

Previous research suggested that various SES markers show differential influences on mental health (Williams, Takeuchi, \& Adair, 1992 as cited in Yu \& Williams, 1999). Particularly, parental educational level has been shown to be a more powerful SES characteristic that influences health of children than does family income (e.g., Wickrama, Conger, Lorenz, \& Elder, 1998). In the present study, SES-based groups' depressive symptom trajectories also suggest that parental education and family poverty exert differential influences on depressive symptom trajectories, and consequently, contribute differentially to variation in SES inequality. The initial inequalities during early adolescence, equalization in adolescence, and differentiation in transition to adulthood were clearer for parental education than for family poverty. For example, education-based group trajectories (Fig. 1) show that even at the peak for high-education group, the level of depressive symptoms does not reach levels experienced by low-education group in early adolescence. Also, the peak of the high-education group is equivalent to the minimum levels experienced by the low-education group in late adolescence. This suggests that although the salience of resources stemming from parental education diminishes during adolescence in general, benefits accrued by high-parental education are strong and stable. Highly educated parents, for instance, have access to better educational institutions and other institutionalized services for their children (Lewis, 2003). Social opportunities/constraints imposed by institutionalization of family inequalities foster differences in youth development, which may contribute to SES-based health inequalities (Walesman et al., 2009). In the long run, parental education more strongly contributes to health inequalities among offspring compared to family poverty through potential institutionalization of family inequalities later in life (Bourdieu, 1990). Although the cumulative accrual of human capital may not be apparent during the more volatile period of adolescence, it may begin to manifest itself during the transition to adulthood with the experiences of key transitional events, such as higher education and full-time employment.

Fig. 1 suggests that adolescents from low-SES families, in terms of parental education, do not overcome a relative disadvantage throughout adolescence and young adulthood.

Although youth from disadvantaged families experience a substantial decline in depressive symptom levels in mid-late adolescence (contributing to equalization), they maintain highlevel depressive symptoms during adolescence. Moreover, youth from disadvantaged families experience a disproportionately larger elevation of depressive symptom levels during transition adulthood compared to youth from advantaged families, driving the differentiation process later in life. Thus, we propose that the equalization of depressive symptoms observed in adolescence across levels of parental education is not only small and short-lived, but it may not benefit the disadvantaged. This is consistent with the relative deprivation hypothesis, which suggests that the social structural influence on mental health problems is more noticeable at the lowest rungs of socioeconomic stratification (Marmot, 1989).

\subsection{Limitations of the study}

Although our findings generally met our expectations and are consistent with previous research, limitations of the current study and recommendations for future research can be identified. First, replication of these findings with samples from true longitudinal designs would provide compelling evidence for the proposed causal pathways. Our findings, derived from sequential survey data, may differ from those obtained using a true longitudinal design 
and are somewhat vulnerable to cohort effects that may heighten significant associations. Second, the six-year gap between the second and third assessments in this study is not optimal. Future efforts to elucidate depressive symptom trajectories across adolescence and young adulthood would benefit from assessments over shorter intervals. Third, this study focused on a limited set of age-graded experiences. Future work should investigate whether other risks/resources, and in particular, extra-familial risks/resources, mediate the observed associations between family SES and depressive symptoms. Fourth, a replication of these findings using clinical mental health and physical health measures would strengthen confidence in the results. In particular, a replication of these findings using other established measures of depressive symptoms (e.g., SCL90 - Derogatis, 1983) and depressive disorders (e.g., DSM-IV) would improve generalizability of the findings. Fifth, although social causation and social selection involving life experiences and health operate alternatively over the life course, this study focused only on social causation wherein family adversity persistently influences youths' mental health. However, impaired mental health may contribute to negative age-based experiences in a manner consistent with a social selection perspective. For example, impaired mental health at age 13 could lead to greater negative life experiences in young adulthood (Wickrama, Conger, et al. 2005; Wickrama, Noh, et al., 2005). Finally, there are potential reciprocal influences between depressive symptoms and individual resources/risks, such as self-esteem and mastery. This reciprocity, or indogeneity, may influence estimations of the influence of time-varying resources/risks on the level of depressive symptoms.

Despite the limitations of this research, these findings have several theoretical and practical implications. This study demonstrates that early social disadvantages have a robust influence on the mental health of adolescents, and suggests that negative health outcomes may be diminished through programs that reduce the impact of family disadvantages and negative age-based experiences. However, there is indication that these programs have not been reaching children and adolescents of extremely disadvantaged families. Rather, our findings suggest that children from extremely disadvantaged families face a persistent heightened risk for distress across all early phases of the life course. Our results emphasize the need for programs that develop early core life resources and confront the occurrence of disrupted transition events. Specific emphasis should be placed on curtailing the apparent reemergence of socioeconomic inequalities as youth enter adulthood. The success of intervention programs illustrates the importance of involving not only disadvantaged families, but also local communities and schools in the initiation and implementation of intervention efforts.

\section{Acknowledgments}

This research is based on data from the Add Health project, a program project designed by J. Richard Udry (PI) and Peter Bearman, and funded by grant P01-HD31921 from the National Institute of Child Health and Human Development to the Carolina Population Center, University of North Carolina at Chapel Hill, with cooperative funding participation by the National Cancer Institute; the National Institute of Alcohol Abuse and Alcoholism; the National Institute on Deafness and Other Communication Disorders; the National Institute on Drug Abuse; the National Institute of General Medical Sciences; the National Institute of Mental Health; the National Institute of Nursing Research; the office of AIDS Research, NIH; the Office of Behavior and Social Science Research, NIH; the Office of the Director, NIH; the Office of Research on Women's Health, NIH; the Office of Population Affairs, DHHS; the National Center for Health Statistics, Centers for Disease Control and Prevention, DHHS; the Office of Minority Health, Centers for Disease Control and Prevention, DHHS; the Office of Minority Health, Office of Public Health and Science, DHHS; the Office of the Assistant Secretary for Planning and Evaluation, DHHS; and the National Science Foundation. Persons interested in obtaining data files from The National Longitudinal Study of Adolescent Health should contact Add Health Project, Carolina Population Center, 123 West Franklin Street, Chapel Hill, NC27516-3997 (addhealth@unc.edu). 


\section{References}

Adler NE, Boyce T, Chesney MA, Cohen S, Folkman S, Kahn RL, et al. Socioeconomic status and health: The challenge of the gradient. American Psychologist. 1994; 49:15-24. [PubMed: 8122813]

Allison, P. Missing data. Thousands Oaks, CA: Sage; 2001.

Arnett JJ. Emerging adulthood: A theory of development from the late teens through the twenties. American Psychologist. 2000; 55:469-480. [PubMed: 10842426]

Bernhardt E, Gahler M, Goldscheider F. The impact of childhood family structure and conflict on routes out of the parental home in Sweden. Acta Sociologica. 2005; 48:99-115.

Blane D, Bartley M, Smith GD, Filakti H, Bethune A, Harding S. Social patterning of medical mortality in youth and early adulthood. Social Science and Medicine. 1994; 39:361-366. [PubMed: 7939852]

Bourdieu, P. The logic of practice. Stanford, CA: Stanford University Press; 1990.

Brody GH, Chen YF, Murry VM, Ge X, Simons RL, Gibbons FX, et al. Perceived discrimination and the adjustment of African American youths: A five-year longitudinal analysis with contextual moderation effects. Child Development. 2006; 77:1170-1189. [PubMed: 16999791]

Brooks-Gunn J, Graber JA, Paikoff RL. Studying links between hormones and negative affect: Models and measures. Journal of Research on Adolescence. 1994; 4:469-486.

Centers for Disease Control and Prevention. Morbidity morality world report. 1996; 45:16-19.

Chantala, K.; Kalsbeek, WD.; Andraca, E. Non-response in wave III of the Add Health Study. 2004. Available at: http://www.cpc.unc.edu/projects/addhealth/pubs/

Chen E, Matthews KA, Boyce WT. Socioeconomic differences in children's health: How and why do these relationships change with age? Psychological Bulletin. 2002; 128:295-329. [PubMed: 11931521]

Conger KJ, Williams ST, Little WM, Maysn KE, Shebloski B. Development of mastery during adolescence: The role of family problem solving. Journal of Health and Social Behavior. 2009; 50:99-114. [PubMed: 19413137]

Conger RD, Ge X, Elder GH Jr, Lorenz FO, Simons RL. Economic stress, coercive family process, and developmental problems of adolescents. Child Development. 1994; 65:541-561. [PubMed: 8013239]

Clausen, J. American lives: Looking back at the children of the great depression. Berkely, CA: University California Press; 1993.

Dannefer D. Cumulative advantage/disadvantage and the life course: Cross-fertilizing age and social science theory. Journals of Gerontology. 2003; 58B:S327-S337. [PubMed: 14614120]

Derogatis, LR. SCL-90-R: Administration, scoring and procedures manual II. 2. Towson, MD: Clinical Psychometric Research; 1983.

Donner A. A review of inference procedures for the intraclass correlation coefficient in the one-way random effects model. International Statistical Review. 1986; 54:67-82.

Duncan, TE.; Duncan, SC.; Strycker, LA.; Li, F.; Alpert, A. An introduction to latent variable growth curve modeling: Concepts, issues, and applications. Mahwah, NJ: Lawrence Erlbaum; 1999.

Elder GH Jr. The life course as developmental theory. Child Development. 1998; 69:1-12. [PubMed: 9499552]

Elder, GH.; George, LK.; Shanahan, MJ. Psychological stress over the life course. In: Kaplan, HB., editor. Psychological stress: Perspective on structure, theory, life course and methods. Orlando, FL: Acadamic Press Course; 1996. p. 247-292.

Ge X, Lorenz FO, Conger RD, Elder GH, Simons RL. Trajectories of stressful life events and depressive symptoms during adolescence. Developmental Psychology. 1994; 30:467-483.

Gore S, Aseltine RH Jr. Race and ethnic differences in depressed mood following the transition from high school. Journal of Health and Social Behavior. 2003; 44:370-389. [PubMed: 14582314]

Hallinan MT, Teixeira RA. Students' interracial friendships: Individual characteristics, structural effects, and racial differences. American Journal of Education. 1987; 95:563-583.

Harper, S.; Lynch, J. Methods for measuring cancer disparities: A review using data relevant to Healthy People 2010 cancer-related objectives. National Cancer Institute; 2006. 
Hatch SL. Conceptualizing and identifying cumulative adversity and protective resources: Implications for understanding health inequalities. Journals of Gerontology. 2005; 60B:130-134. [PubMed: 16251584]

Hayward MD, Gorman BK. The long-arm of childhood: The influence of early-life social conditions on men's mortality. Demography. 2004; 41:80-107.

House JS, Lantz PM, Herd P. Continuity and change in the social stratification of aging and health over the life course: Evidence from a nationally representative longitudinal study from 1986 to 2001/2002 (Americans Changing Lives Study). Journals of Gerontology. 2005; 60B:S15-S26.

Jackson PB. Health inequalities among minority populations. Journals of Gerontology. 2006; 60B:6367.

Kerckhoff, AC. The transition from school to work. In: Mortimer, JT.; Larson, RW., editors. The changing adolescent experience: Societal trends and the transition to adulthood. New York: Cambridge University Press; 2002.

Kreiter, MS. Grown up at 21? No way. Washington, DC: United Press International; 2003.

Koivusilta LK, Rimpelä AH, Kautiainen SM. Health inequality in adolescence. Does stratification occur by familial social background, family affluence, or personal social position? BMC Public Health. 2006; 6:110. http://www.biomedcentral.com/1471-2458/6/110. [PubMed: 16643660]

Larson RW, Moneta G, Richards MH, Wilson S. Continuity, stability, and change in daily emotional experience across adolescence. Child Development. 2002; 73:1151-1165. [PubMed: 12146740]

Lewis, AE. Race in the schoolyard: Negotiating the color line in classrooms and communities. Piscataway, NJ: Rutgers University Press; 2003.

Link BG, Phelan J. Social conditions as fundamental causes of disease. Journal of Health and Social Behavior. 1995; 36:80-94. [PubMed: 7560851]

Lynch SM. Cohort and life-course patterns in the relationship between education and health: A hierarchical approach. Demography. 2003; 40:309-331. [PubMed: 12846134]

Marmot, MG. General approaches to migrant studies: The relation between disease, social class and ethnic origin. In: Cruickshank, JK.; Beevers, DG., editors. Ethnic factors in health and disease. London: Butterworth; 1989.

Matjasko JL, Grunden LN, Ernst JL. Structural and dynamic process family risk factors: Consequences for holistic adolescent functioning. Journal of Marriage and Family. 2007; 69:654-674.

Mathews, TJ.; Hamilton, BE. Mean age of mother 1970-2000. Vol. 51. Centers for Disease Control, National Vital Statistics Reports; 2002.

Merton RK. The Matthew effect in science. II: Cumulative advantage and the symbolism of intellectual property. Isis. 1988; 79:606-623.

Miech RA, Eaton WW, Brennan K. Mental health disparities across education and sex: A prospective analysis examining how they persist over the life course. Journals of Gerontology. 2005; 60B:9398. [PubMed: 16251598]

Meich RA, Shanahan MJ. Socioeconomic status and depression over the life course. Journal of Health and Social Behavior. 2000; 41:162-176.

Moneta GB, Schneider B, Csikszentmihalyi M. A longitudinal study of the self-concept and experiential components of self-worth and affect across adolescence. Applied Developmental Science. 2001; 5:125-142.

Moody J. Race, school integration, and friendship segregation in America. American Journal of Sociology. 2001; 107:679-716.

Mortimer, JT.; Larson, RW., editors. The changing adolescent experience: Societal trends and the transition to adulthood. New York: Cambridge University Press; 2002.

Noh S, Beiser M, Kaspar V, Hou F, Rummens J. Perceived racial discrimination, depression, and coping: A study of Southeast Asian refugees in Canada. Journal of Health and Social Behavior. 1999; 40:193-207. [PubMed: 10513144]

O'Rand AM. The precious and the precocious: Understanding cumulative disadvantage and cumulative advantage over the life course. Gerontologist. 1996; 36:230-238. [PubMed: 8920094] 
O'Rand AM, Hamil-Luker J. Processes of cumulative adversity: Childhood disadvantage and increased risk of heart attack across the life course. Journals of Gerontology. 2005; 60B:S117S124.

Osgood, WD.; Ruth, G.; Eccles, JS.; Jacobs, JE.; Barber, BL. Six paths to adulthood: Fast starters, parents without careers, educated partners, educated singles, working singles, and slow starters. In: Settersten, RA., Jr; Furstenberg, FF., Jr; Rumbaut, RG., editors. On the frontier of adulthood: Theory, research, and public policy. Chicago, IL: University of Chicago Press; 2005.

Pearlin LI. The sociological study of stress. Journal of Health and Social Behavior. 1989; 30:241-256. [PubMed: 2674272]

Power C, Hertzman C, Matthews S, Manor O. Social differences in health: Life-cycle effects between ages 23 and 33 in the 1958 British Birth Cohort. American Journal of Public Health. 1997; 87:1499-1503. [PubMed: 9314803]

Prus SG. Age, SES, and health: A population level analysis of health inequalities over the lifecourse. Sociology of Health and Illness. 2007; 29:275-296. [PubMed: 17381817]

Radloff LS. The CES-D scale: A self-report depression scale for research in the general population. Applied Psychological Measurement. 1977; 1:385-401.

Radloff LS. The use of the Center for Epidemiologic Studies Depression Scale in adolescents and young adults. Journal of Youth and Adolescence. 1991; 20:149-166.

Raudenbush, SW.; Bryk, AS. Hierarchical linear models: Applications and data analysis methods. 2. Thousand Oaks, CA: Sage Publications; 2002.

Robinson R. The fetal origins of adult disease. British Medical Journal. 2001; 322:375-376. [PubMed: 11179140]

Rosenberg, M. Society and adolescent self-image. Princeton, NJ: Princeton University Press; 1965.

Ross CE, Wu CL. Education, age, and the cumulative advantage in health. Journal of Health and Social Behavior. 1996; 37:104-120. [PubMed: 8820314]

Sampson, RJ.; Laub, JR. Crime in the making: Pathways and turning points through life. Cambridge, MA: Harvard University Press; 1993.

Sandefur, GD.; Eggerling-Boeck, J.; Park, H. Off to a good start? Postsecondary education and early adult life. In: Settersten, RA., Jr; Furstenberg, FF., Jr; Rumbaut, RG., editors. On the frontier of adulthood: Theory, research, and public policy. Chicago, IL: University of Chicago Press; 2005.

Scaramella LV, Conger RD, Simons RL, Whitbeck LB. Predicting risk for pregnancy by late adolescence: A social contextual perspective. Developmental Psychology. 1998; 34:1233-1245. [PubMed: 9823508]

Schoeni, RF.; Ross, KE. Material assistance from families during the transition to adulthood. In: Settersten, RA., Jr; Furstenberg, FF., Jr; Rumbaut, RG., editors. On the frontier of adulthood: Theory, research and public policy. Chicago, IL: The University of Chicago Press; 2005.

Shanahan MJ. Pathways to adulthood in changing societies: Variability and mechanisms in life course perspective. Annual Review of Sociology. 2000; 26:667-692.

Spencer, MB. Resiliency and fragility factors associated with the contextual experiences of lowresource urban African-American male youth and families. In: Booth, A.; Crouter, AC., editors. Does it take a village? Community effects on children, adolescents, and families. Mahwah, NJ: Lawrence Erlbaum Associates, Inc; 2001.

Sroufe, AL.; Duggal, S.; Weinfield, N.; Carlson, E. Relationships, development, and psychopathology. In: Sameroff, AJ.; Lewis, M.; Miller, SM., editors. Handbook of developmental psychopathology. 2. New York: Kluwer Academic/Plenum Publishers; 2000.

Steinberg L, Lamborn SD, Darling N, Mounts NS, Dornbusch SM. Over-time changes in adjustment and competence among adolescents from authoritative, authoritarian, indulgent, and neglectful families. Child Development. 1994; 65:754-770. [PubMed: 8045165]

Turner R, Noh S. Class and psychological vulnerability among women: The significance of social support and personal control. Journal of Health and Social Behavior. 1983:242-315.

Turner RJ, Wheaton B, Lloyd DA. The epidemiology of social stress. American Sociological Review. 1995; 60:104-125. 
Walesman MK, Gee GC, Geronimus AT. Ethnic differences in trajectories of depressive symptoms: Disadvantage in family background, high school experiences, and adult characteristics. Journal of Health and Social Behavior. 2009; 50:82-97. [PubMed: 19413136]

West P. Health inequalities in the early years: Is there equalization in youth? Social Science and Medicine. 1997; 44:833-858. [PubMed: 9080566]

Wheaton B, Clarke P. Space meets time: Integrating temporal and contextual influences on mental health in early adulthood. American Sociological Review. 2003; 68:680-706.

Whitbeck LB, Simons RL, Conger RD, Lorenz FOSH, Elder GH Jr. Family economic hardship, parental support, and adolescent self-esteem. Social Psychology Quarterly. 1991; 54:353-363.

Whitbeck LB, Simons RL, Conger RD, Wickrama KAS, Ackley KA, Elder GH Jr. The effects of parents' working conditions and family economic hardship on parenting behaviors and children's self-efficacy. Social Psychology Quarterly. 1997; 60:291-303.

Wickrama KAS, Bryant CM. Community context of social resources and adolescent mental health. Journal of Marriage and Family. 2003; 65:850-866.

Wickrama KAS, Conger RD, Abraham WT. Early adversity and later health: The intergenerational transmission of adversity through mental disorder and physical illness. Journals of Gerontology. 2005; 60B:125-129. [PubMed: 16251583]

Wickrama KAS, Conger RD, Lorenz FO, ElderF GH Jr. Parental education and adolescent selfreported physical health. Journal of Marriage and the Family. 1998; 60:967-978.

Wickrama KAS, Conger RD, Wallace LE, Elder GH Jr. Linking early social risks to impaired physical health during the transition to adulthood. Journal of Health and Social Behavior. 2003; 44:61-74. [PubMed: 12751311]

Wickrama KAS, Noh S. The long arm of community: The influence of childhood community contexts across the early life course. Journal of Youth and Adolescence (available online). 2009

Wickrama KAS, Noh S, Bryant CM. Racial differences in adolescent distress: Differential effects of the family and community for blacks and whites. Journal of Community Psychology. 2005; 33:261-282.

Williams DR. The health of U.S. racial and ethnic populations. Journals of Gerontology. 2005; 60B:S53-S62.

Wilson AE, Shuey KM, Elder GH Jr. Cumulative advantage processes as mechanisms of inequality in life course health. American Journal of Sociology. 2007; 12:1886-1924.

Yu, Y.; Williams, DR. Social class. In: Aneshensel, CS.; Phelan, JC., editors. Handbook of Sociology of mental health. New York: Kluwer Academic/Plenum Publishers; 1999. 


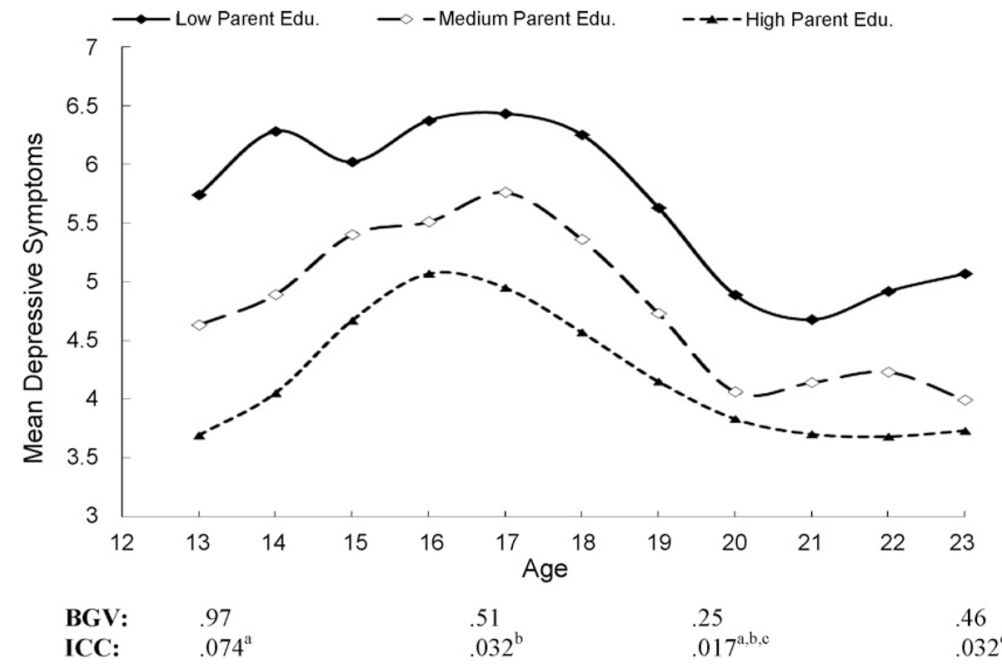

$\mathrm{BGV}=$ Between group variance. $\mathrm{ICC}=$ Intra-class correlation. Coefficients marked with different characters $(a, b, c)$ indicate significant differences in ICCs.

Fig. 1.

Depressive symptom trajectories by levels of parental education. BGV = between-group variance. $\mathrm{ICC}=$ intra-class correlation. Coefficients marked with different characters $(\mathrm{a}-\mathrm{c})$ indicate significant differences in ICCs. 


\section{Table 1}

Descriptive statistics of depressive symptoms by age.

\begin{tabular}{|llll|}
\hline Age (years) & $\boldsymbol{M}$ & $\boldsymbol{S} \boldsymbol{D}$ & $\boldsymbol{N}$ \\
\hline 13 & 4.52 & 3.54 & 1979 \\
14 & 4.84 & 3.75 & 3188 \\
15 & 5.31 & 3.88 & 3913 \\
16 & 5.53 & 3.84 & 4511 \\
17 & 5.69 & 3.96 & 4072 \\
18 & 5.34 & 3.89 & 2896 \\
19 & 4.73 & 3.99 & 2200 \\
20 & 4.11 & 3.69 & 1825 \\
21 & 4.11 & 3.80 & 2194 \\
22 & 4.21 & 3.82 & 2319 \\
23 & 4.11 & 3.87 & 1755 \\
\hline
\end{tabular}




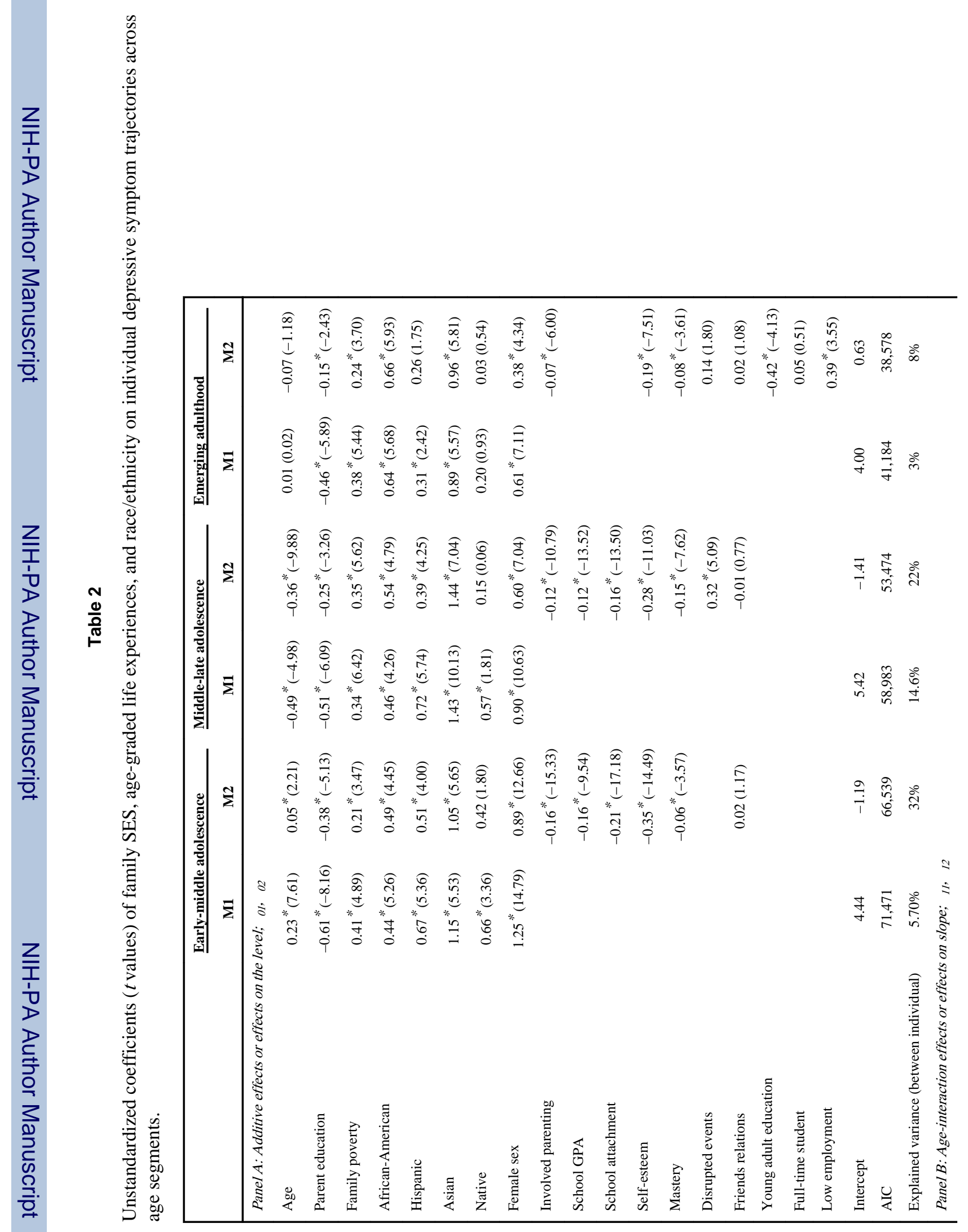

Adv Life Course Res. Author manuscript; available in PMC 2013 October 28. 


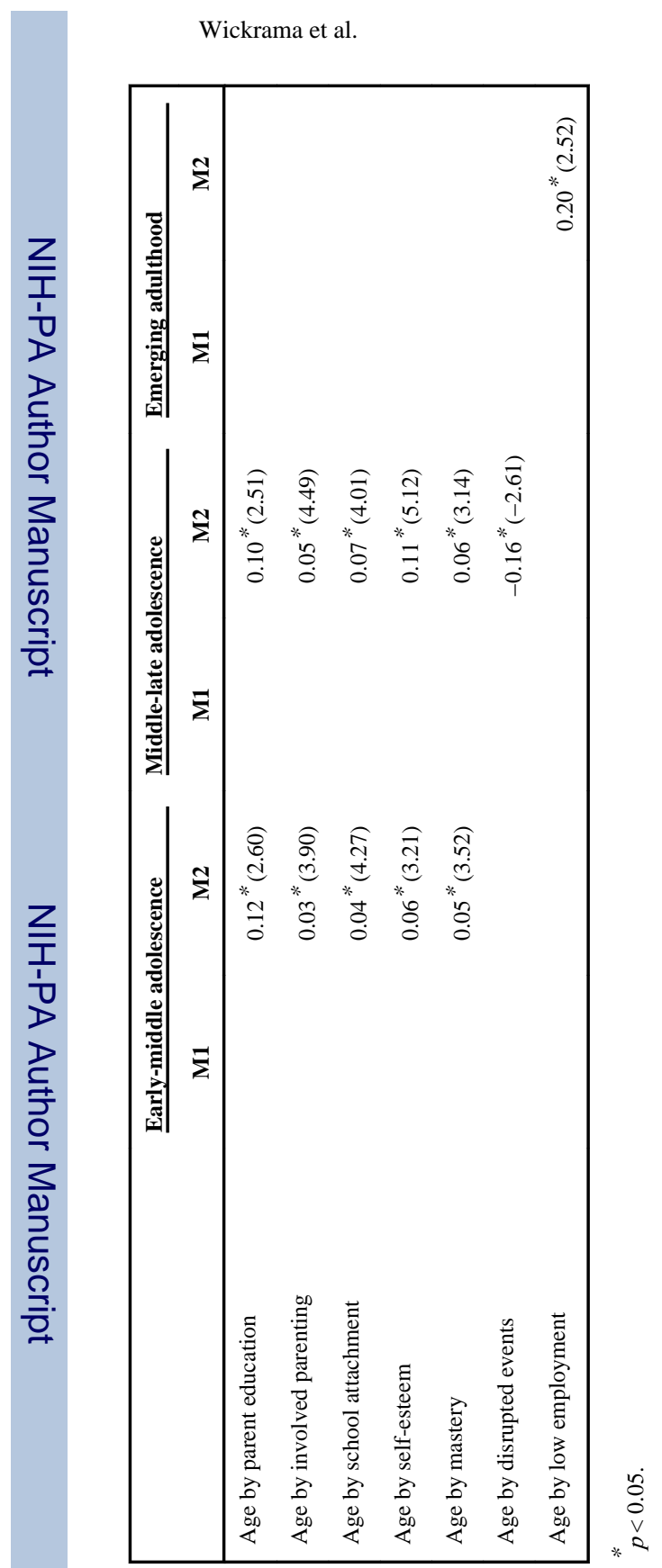

Page 26 
